\title{
Phytotoxic Potential of Zanthoxylum affine and Its Major Compound Linarin as a Possible Natural Herbicide
}

\author{
María Yolanda Rios, ${ }^{*}, \dagger, \S \odot$ Liliana Carolina Córdova-Albores, ${ }^{\dagger, \S}$ M. Ángeles Ramírez-Cisneros, ${ }^{\dagger, \S(1) ~}$ \\ Beatriz King-Díaz, ${ }^{\dagger}$ Blas Lotina-Hennsen, ${ }^{\dagger}$ Ismael León Rivera, ${ }^{\dagger, \S}$ and Diter Miranda-Sánchez ${ }^{\dagger, \S}$ \\ ${ }^{\dagger}$ Centro de Investigaciones Químicas, IICBA, Universidad Autónoma del Estado de Morelos, Av. Universidad 1001, Col. Chamilpa, \\ 62209 Cuernavaca, Morelos, Mexico
}

${ }^{\ddagger}$ Departamento de Bioquímica, Facultad de Química, Universidad Nacional Autónoma de México, Ciudad Universitaria, 04510 México D.F., Mexico

Supporting Information

\begin{abstract}
Four compounds, the flavone linarin (1), the triterpene lupenone (2), the tocopherol (vitamin E, 3), and the new natural alkaloid 1,2,3,4-tetrahydro-1,1-dimethyl-6,7-isoquinolindiol (affineine, 4), were the major natural products isolated from Zanthoxylum affine (syn. Zanthoxylum fagara, Rutaceae). Compound $\mathbf{1}$ is highly abundant in this plant and was isolated as a white precipitate obtained from the acetone and methanol extracts. The structure of these four compounds was established by $1 \mathrm{D}$ and $2 \mathrm{D}$ NMR spectroscopy including ${ }^{1} \mathrm{H},{ }^{13} \mathrm{C}$, DEPT, COSY, HSQC, and HMBC experiments. The hexane, acetone, and methanol extracts, as well as 1, were evaluated for their potential phytotoxic effects in pre- and post-emergent assays, as well as to identify their mechanisms of action. As pre-emergent phytotoxic agents, the hexane, acetone, and methanol extracts inhibited germination and residual growth (root and stem elongation) of Lactuca sativa (lettuce) and Lolium perenne (perennial ryegrass). As post-emergent agents, they inhibited dry biomass. Compound $\mathbf{1}$ acts as a pre-emergent herbicide, by inhibiting germination, seed respiration, residual seedling growth and, notably, root hair development. Furthermore, 1 inhibited the synthesis of ATP and the electron transport chain of isolated spinach chloroplasts; in this way, it behaves as a Hill reaction inhibitor. The site of inhibition was located at the donor site of PSII from the oxygen evolving complex to $Q_{A}$, thus acting as a multisite compound. These results suggest that compound $\mathbf{1}$ can be used as a lead for a potential green herbicide with different targets.
\end{abstract}

\section{INTRODUCTION}

The interaction of plants with different organisms has resulted in the development of defense mechanisms such as the production of secondary metabolites. These are synthesized in the roots, stems, leaves, and flowers. ${ }^{1}$ A wide array of biologically active secondary metabolites possesses a variety of natural functions; among these functions is their potential use as pesticides in agriculture. ${ }^{2}$ These characteristics make secondary metabolites excellent candidates for obtaining compounds with herbicidal properties, which, ideally, exhibit biological activities at lower concentrations than those derived from chemical synthesis. ${ }^{3}$

The genus Zanthoxylum is the most primitive member of the Rutaceae family. This genus is a large and complex group of small trees and shrubs composed of about 250 species, mainly growing in tropical and temperate regions of the world.,5 Many of its species are used as food or as therapeutic remedies and are known to produce a variety of biologically active secondary metabolites including alkaloids, terpenes, lignans, steroids, coumarins, and flavonoids. ${ }^{6,7}$ Additionally, there are reports of Zanthoxylum species with bactericidal, ${ }^{8,9}$ insectici- dal, ${ }^{10-12}$ fungicidal, ${ }^{13,14}$ nematicidal, ${ }^{15,16}$ and allelopathic activities. ${ }^{17-19}$ For example, the allelopathic effects of the aqueous leaves' extract of Zanthoxylum bungeanum on the germination rate of Medicago sativa, Lactuca sativa, and Raphanus sativa have been evaluated; and the results showed an inhibitory activity $(80,70$, and $90 \%$, respectively) at 25 or $50 \mathrm{~g} \mathrm{~L}^{-1}$. ${ }^{18}$ The compound xanthoxyline was isolated from the fruits of Zanthoxylum limonella, which showed inhibitory effects against the germination of Amaranthus tricolor and Echinochloa crus-galli. ${ }^{17}$ Aqueous extracts $(10 \% \mathrm{w} / \mathrm{v})$ of leaves and stems of Zanthoxylum schinifolium showed a concentration-dependent inhibitory activity against germination and seedling growth of Triticum sativum (wheat). ${ }^{19}$ Zanthoxylum affine is a shrub widely distributed in America, particularly in Florida, northern Mexico, the Caribbean, Guatemala, Colombia, and Brazil. This species is found in the tropics and

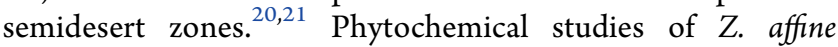

Received: August 14, 2018

Accepted: October 22, 2018

Published: November 2, 2018 
reported laurifoline, magnoflorine, ${ }^{20}$ skimmianin, scopoletin, ${ }^{7}$ synephrine, ${ }^{22}$ castanaguyone, $^{23}$ and meridinol ${ }^{24}$ as its secondary metabolites. Biological activities have been reported for these species including antibacterial, ${ }^{21,25}$ larvicidal, $^{26}$ and antifungal properties. ${ }^{5,21}$ The plant-plant and plant-microorganisms interactions make the synthesis of some of these secondary metabolites possible by plants, and therefore, it is highly probable to find in this work a new natural lead with potential herbicide activity. The aim of this research was to evaluate the phytotoxic potential of the $Z$. affine organic extracts, and its major constituent linarin (1), on L. sativa and Lolium perenne seeds and plants, in pre- and post-emergent assays, additionally, to know if $\mathbf{1}$ 's behavior can be used as a potential herbicide and to identify its possible mechanisms of action as plant growth inhibitor.

\section{RESULTS AND DISCUSSION}

Identification of the Chemical Compounds. Four compounds were isolated as major natural products from $Z$. affine (Figure 1). On the basis of their NMR spectroscopic data

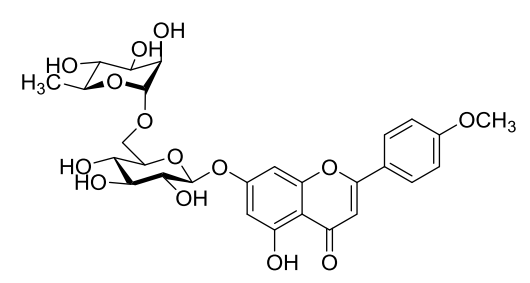

1

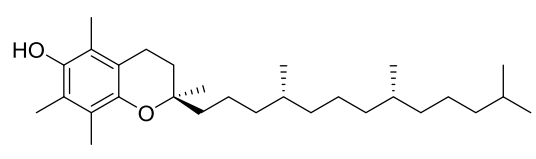

3
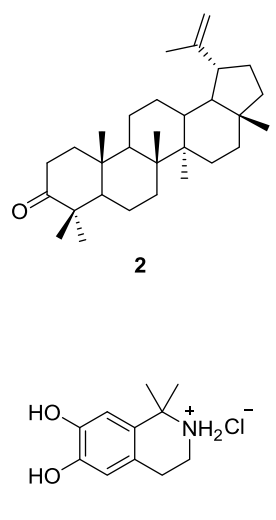

4
Figure 1. Chemical compounds from Z. affine.

and comparison with those reported in literature, these compounds were identified as linarin (1) ${ }^{27}$ lupenone (2), ${ }^{28}$ vitamin E (3), ${ }^{29}$ and the new natural product affineine (4). ${ }^{30}$ The integral value of the amine hydrogen on ${ }^{1} \mathrm{H}$ NMR spectra of 4 suggested that this product is a protonated amine, which was confirmed by X-ray crystallography (Figures 1, 2, and S20).

Crystallographic data for 4 has been deposited at the Cambridge Crystallographic Data Centre (CCDC 1840709, Figure 2).

Quantification of Linarin (1) in the Acetone and Methanol Extracts. Linarin (1) was isolated as a white precipitate directly from the acetone and methanol extracts. The remnant proportion of $\mathbf{1}$ in all extracts was determined by high-performance liquid chromatography-mass spectrometry (HPLC-MS), representing $1.42 \%$ of the acetone extract and was not detected in the hexane and methanol extracts, according to the analysis conditions in the section "Quantification 1) in the Acetone and Methanol Extracts".

Pre-emergent Bioassays. Effect on Seed Germination and Residual Seedling Growth of Mono- and Di-cot Plants Treated with the Organic Extracts. To know the effects of $Z$. affine extracts and linarin as pre-emergent inhibitors, they were assayed at two concentrations (50 and $100 \mathrm{mg} \mathrm{L}^{-1}$ extracts, and 50 and $100 \mu \mathrm{M}$ linarin) on germination and residual

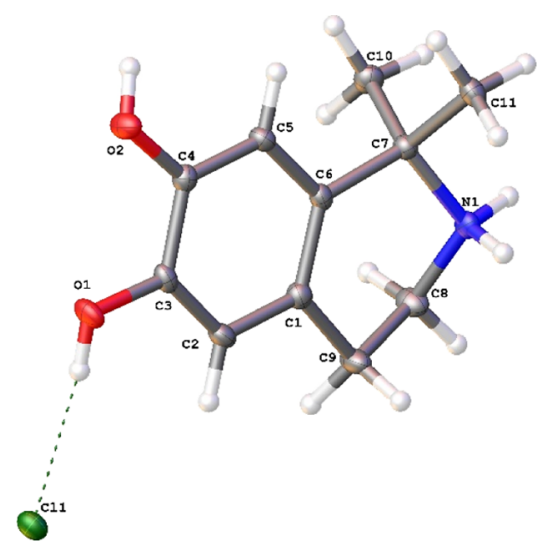

Figure 2. ORTEP projection of 1,2,3,4-tetrahydro-1,1-dimethyl-6,7isoquinolindiol (affineine, 4).

seedling growth (root and stem elongation) of L. sativa and $L$. perenne. In general, L. sativa showed higher sensitivity to the extracts at $100 \mathrm{mg} \mathrm{L}^{-1}$, its germination being more affected by the hexane extract $(61.6 \%)$, followed by the methanol extract $(46.6 \%)$ and then the acetone extract (30.8\%) (Figure 3).

However, the residual root elongation in this species was more affected by the acetone extract with 57.5 and $51.45 \%$ at 50 and $100 \mathrm{mg} \mathrm{L}^{-1}$, respectively. The methanol extract also inhibited this activity in $42.8 \%$ and the hexane extract showed minor inhibition with $33.9 \%$, both at $100 \mathrm{mg} \mathrm{L}^{-1}$. Residual elongation of $L$. sativa stems were affected by the methanol (34.2\% at $100 \mathrm{mg} \mathrm{L}^{-1}$ ) and acetone extracts (32.5 and $27.1 \%$ at 50 and $100 \mathrm{mg} \mathrm{L}^{-1}$, respectively), whereas the hexane extract was not active on this test.

On the other hand, germination of $L$. perenne seeds was inhibited by the acetone and methanol extracts (16-25\%). The better activity of the three extracts was observed in the residual root growth, being the acetone extract the most active with 40.6 and $64.4 \%$ at 50 and $100 \mathrm{mg} \mathrm{L}^{-1}$, respectively. The hexane extract showed similar effects with 39.4 and $57.9 \%$ at the same concentrations. The methanol extract inhibited germination in a minor grade than the other two extracts (40.3 and $43.3 \%$ at 50 and $100 \mathrm{mg} \mathrm{L}^{-1}$, respectively) (Figure 3 ).

As linarin (1) was obtained as the major compound from the acetone extract and $Z$. affine, its effects on the germination and residual seedling growth (root and stem elongation) on $L$. sativa and $L$. perenne were assayed. Compound 1 did not show a dose-dependent response because at 50 and $100 \mu \mathrm{M}$ it inhibited seed germination of L. sativa by the same percentage, $88.6 \%$. The effect of 1 on seed germination, residual root development and stem development of $L$. perenne was minor as shown in Figure 4. Therefore, compound $\mathbf{1}$ acts specifically as an inhibitor of $L$. sativa species. These results suggest that the chemical composition of each extract plays an important role in the inhibition of germination and residual seedling growth of the species assayed.

According to Hanley and Whiting, the effects of a compound on seed germination and plant growth can vary from one plant species to another. ${ }^{31}$ One factor is the size, affinity, and permeability of the tegument of the seed assayed. Additionally, the susceptibility of mono- and di-cot plants species to phytotoxic compounds in laboratory conditions depends on the physiological and biochemical characteristics of each plant. $^{32}$ It is well known that $L$. sativa is a plant with fast germination and shows high sensitivity; ${ }^{33-35}$ however, the 


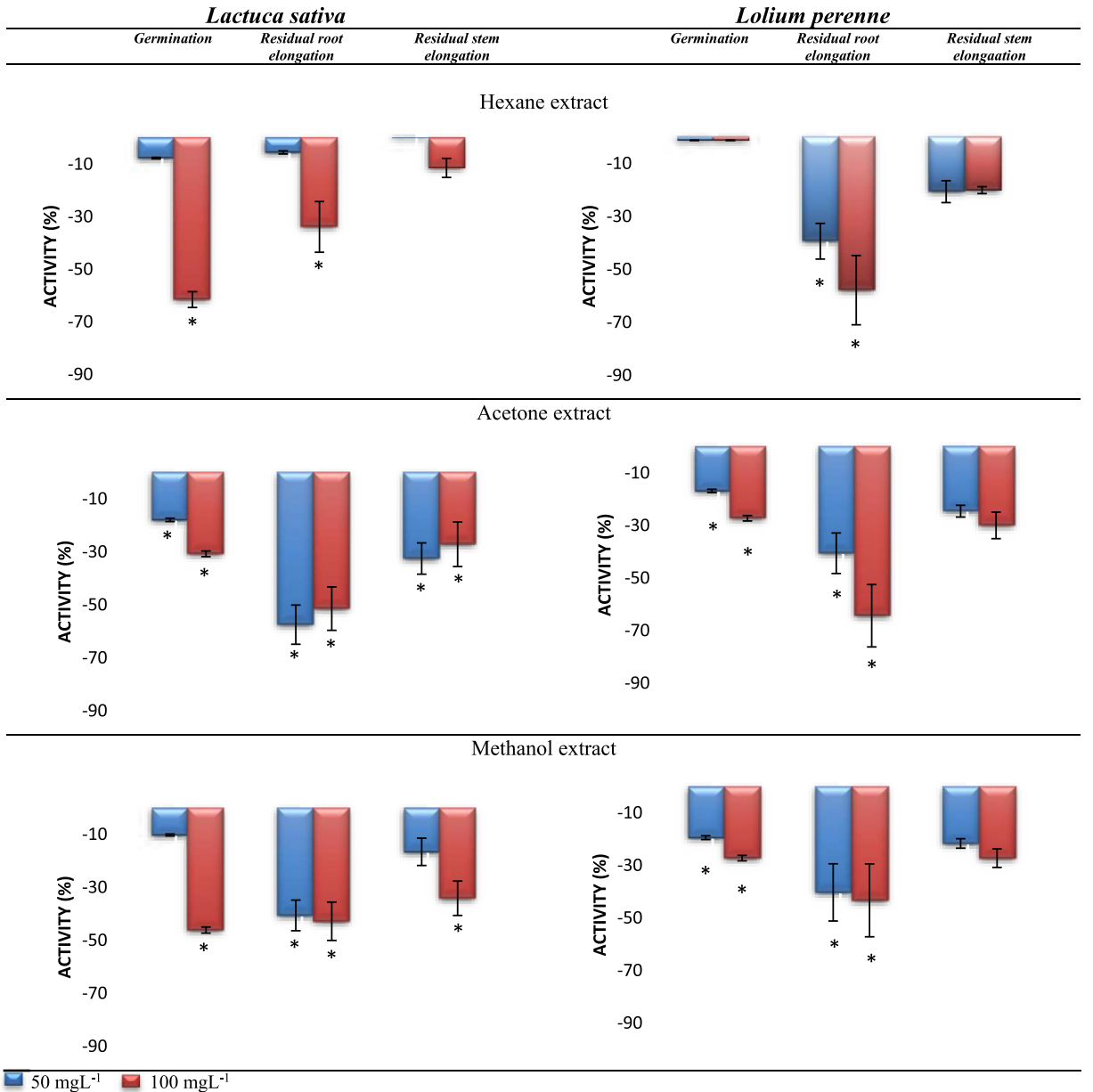

Figure 3. Effect of $Z$. affine extracts on germination and residual seedling growth of L. sativa and L. perenne. Data represent the \% of inhibition (negative values) or enhances (positive values) $\pm \mathrm{SD} ; n=3$, *statistical differences $(p<0.05)$ according to Holm-Sidak to germination and Dunn's to residual root and stem elongation with control value $=0 \%$.

\begin{tabular}{|c|c|c|c|c|c|c|c|c|}
\hline & \multicolumn{4}{|c|}{ Lactuca sativa } & \multicolumn{4}{|c|}{ Lolium perenne } \\
\hline & & Germination & $\begin{array}{c}\begin{array}{c}\text { Residual root } \\
\text { elongation }\end{array} \\
\end{array}$ & $\begin{array}{c}\text { Residual stem } \\
\text { elongation }\end{array}$ & & Germination & $\begin{array}{c}\text { Residual root } \\
\text { elongation }\end{array}$ & $\begin{array}{c}\text { Residual stem } \\
\text { elongaation }\end{array}$ \\
\hline \multirow{9}{*}{ 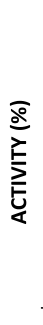 } & 60 & & & $*$ & 60 & & & \\
\hline & 40 & & & $I$ & 40 & & & \\
\hline & 20 & & & & 20 & & & \\
\hline & 0 & 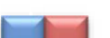 & 10 & & $\frac{\partial}{2}$ & 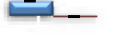 & 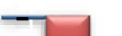 & $\leftrightharpoons-$ \\
\hline & -20 & & & & -20 & & & \\
\hline & -40 & & & & -40 & & * & \\
\hline & -60 & & & & -60 & & & \\
\hline & -80 & $T$ & & + & -80 & & & \\
\hline & -100 & $\frac{1}{*}$ & * & $*$ & -100 & & & \\
\hline
\end{tabular}

Figure 4. Effect of linarin (1) on germination and residual seedling growth of L. sativa and L. perenne. Data represent the \% of inhibition (negative values) or enhances (positive values) $\pm \mathrm{SD} ; n=3$, *statistical differences $(p<0.05)$ according to Holm-Sidak to germination and Dunn's to root and stem elongation with control value $=0 \%$.

impact of the extracts was more evident on germination of $L$. sativa.

As mentioned above, the permeability of tegument provides a first barrier in protecting the embryo against phytotoxic compounds. However, once the germination process is carried out, roots are exposed to any chemical agent, in both species tested, residual root elongation showed susceptibility to all extracts, especially to the acetonic extract.
Effect of Linarin (1) on Seed Respiration. Seed respiration of L. sativa was decreased with linarin (1) treatment with a concentration-dependent pattern (Figure 5) from the 12 to 72 h. These results indicate that $\mathbf{1}$ acts as a seed respiration inhibitor. L. sativa seed respiration was inhibited up to $70 \%$ with a concentration of $50 \mu \mathrm{M}$ of compound 1 . These results suggest that processes related to respiration, such as glycolysis or the mobilization of reserve carbohydrates are being limited. 


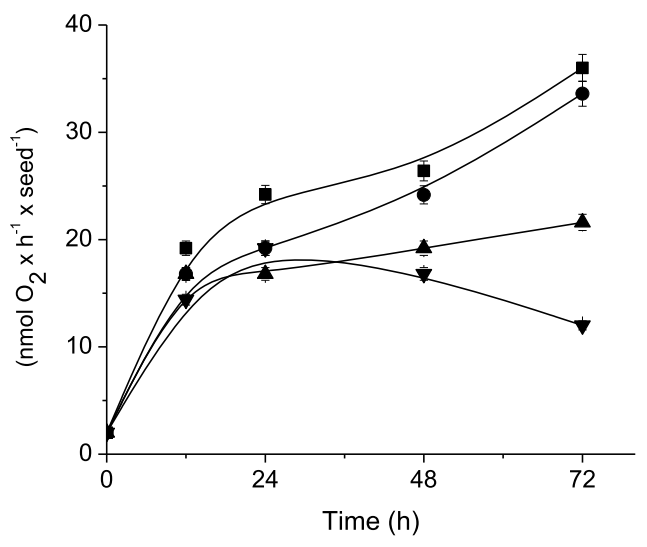

Figure 5. Effect of increasing concentrations of linarin (1) on seed respiration of $L$. sativa. Seeds previously imbibed with $0.0(\mathbf{\square}), 12.5$ $(\boldsymbol{\bullet}), 25.0(\mathbf{\Delta})$, and $50.0(\boldsymbol{\nabla}) \mu \mathrm{M}$ of 1 expressed as $\mathrm{nmol} \mathrm{O}_{2} \mathrm{~h}^{-1}$ seed $^{-1}$. Statistical differences are significant $(p<0.05)$ by Tukey test, $n=3$.

Because of the respiration of seeds at $72 \mathrm{~h}$ of germination with $50 \mu \mathrm{M}$ of 1 being decreased $66.7 \%$ with respect to control, and in this time the roots of control seedlings began to grow, microscopic observations of the roots growth on control and treated samples showed notable differences. In Figure 6, it

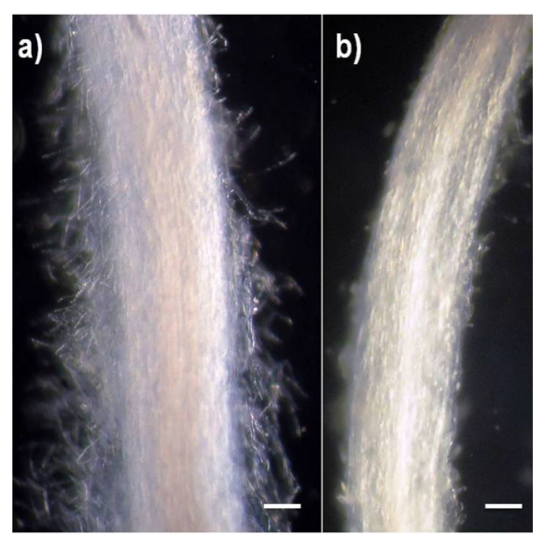

Figure 6. L. sativa root hair development ( $1 \mathrm{~mm}$ over root apical meristem, $\times 200$, polarized light) at $72 \mathrm{~h}$ old in (a) control and (b) roots treated with linarin $100 \mu \mathrm{M}$ bar: $0.1 \mathrm{~mm}$.

is shown that root hairs decreased with compound $\mathbf{1}$ at 100 $\mu \mathrm{M}$ with respect to the control. The root hairs, derived from root epidermal cells, have an important function in the uptake of nutrient and water, as well as, anchoring the root in the soil. ${ }^{36}$ Root development involves various transcription factors, as well as plant hormones and external factors, biotic or abiotic. These can impact root development by modulating these morphogenetic processes. ${ }^{37}$ Therefore, linarin can acts as a natural herbicide by inhibiting, root hair development.

Post-emergent Bioassays. Light Reaction of Photosynthesis in Vitro. ATP Synthesis. Because linarin (1) can act as a pre-emergent inhibitor, it is important to know if this compound also shows post-emergent inhibition; in this case, we measured the ATP formation in illuminated thylakoids in the presence of increasing concentrations of $\mathbf{1}$, and the results showed that this compound at $150 \mu \mathrm{M}$ inhibited ATPsynthesis by $61 \%$ (Figure 7 ).

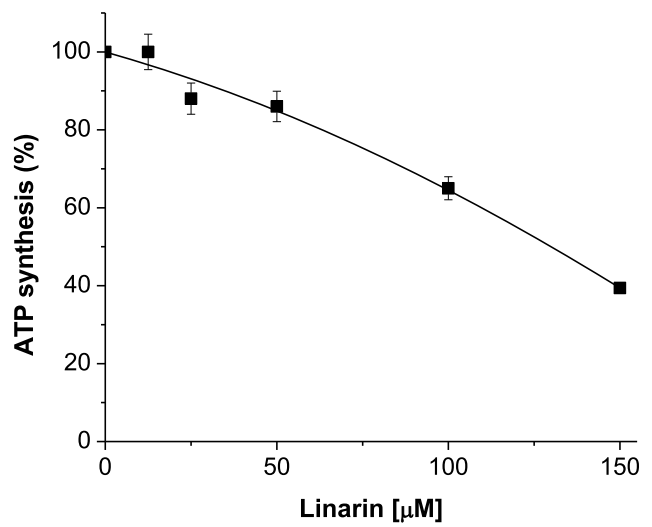

Figure 7. Effect of linarin (1) on ATP synthesis. $733 \mu \mathrm{M} \mathrm{ATP} / \mathrm{mg}$ $\mathrm{Chl} \cdot \mathrm{h}$ was used as control. The data represent the mean $\pm \mathrm{SD}, n=3$.

Effect of Linarin on Noncyclic Electron Transport Rate on Spinach Thylakoids. The light-dependent photophosphorylation is coupled to electron transport. Thus, ATP formation can be inhibited by either blockage of the electron transport, by direct inhibition of the $\mathrm{H}^{+}$-ATPase, or by uncoupling of the ATP synthesis process from the electron transport. ${ }^{38}$ To discern between these mechanisms, linarin (1) was evaluated under basal, phosphorylating, and uncoupled conditions at increasing concentrations. 1 inhibited the noncyclic electron transport in the three conditions, with $\mathrm{IC}_{50}$ values for phosphorylating and uncoupled electron transport of 134.5 and $150 \mu \mathrm{M}$, respectively, being similar to the previously reported flavonoids quercetin, apigenin, genistein, and eupatorin, all of them with an $\mathrm{IC}_{50}$ from 30 to $200 \mu \mathrm{M}$. $^{38}$ Furthermore, 1 inhibited basal electron transport partially; however, the $\mathrm{IC}_{50}$ value for this condition was not obtained (Figure 8). These results indicate that $\mathbf{1}$ acts as a mild Hill reaction inhibitor, measured from water to methyl viologen (MV).

Effect of Linarin on Electron Flow of PSII and PSI. To locate the inhibition site of linarin (1) on the thylakoid electron transport chain, increasing concentrations of $\mathbf{1}$ were tested on uncoupled electron transport of PSII, PSI, and partial reactions in the presence of appropriate artificial donors and

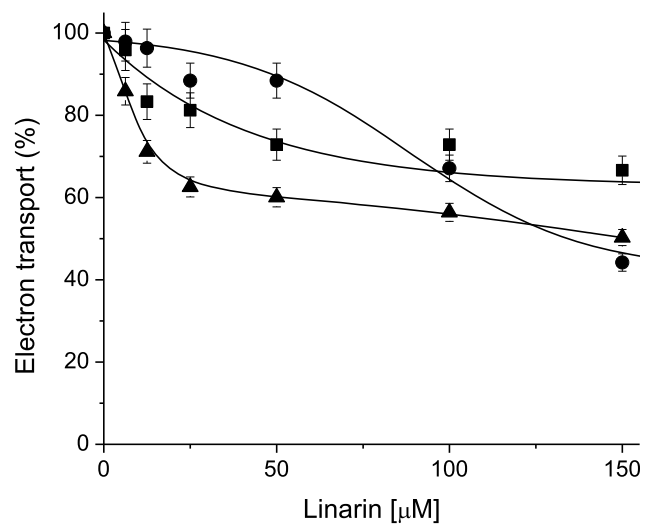

Figure 8. Effect of linarin (1) on noncyclic electron transport basal $(\boldsymbol{\square})$, phosphorylating $(\mathbf{O})$, and uncoupled $(\boldsymbol{A})$. Control values were 467, 933, and 1067 for basal, phosphorylating, and uncoupled electron transport flow, respectively. The data represent the mean \pm $\mathrm{SD}, n=3$. 
electron acceptors, as well as inhibitors, of the electron transport chain (Table 1).

\section{Table 1. Effect of 1 on Partial Reactions of PSII ${ }^{a}$}

\begin{tabular}{lcc} 
& \multicolumn{2}{c}{ photosystem II } \\
\cline { 2 - 3 } conc. $(\mu \mathrm{M})$ & $\mathrm{H}_{2} \mathrm{O}$ to DCBQ & $\mathrm{H}_{2} \mathrm{O}$ to $\mathrm{SiMo}$ \\
0.0 & $400.0 \pm 17.4$ & $534.0 \pm 23.7$ \\
12.5 & $399.9 \pm 21.5$ & $400.0 \pm 22.7$ \\
25.0 & $0.0 \pm 0.0$ & $267.0 \pm 11.8$ \\
50.0 & & $266.6 \pm 15.1$ \\
100.0 & & $134.0 \pm 5.9$
\end{tabular}

${ }^{a}$ Data represent the mean $\pm \mathrm{SD}, n=3$.

The results indicated that 1 inhibited $100 \%$ the uncoupled PSII measured from water to 2,5-dichloro-1,4-benzoquinone (DCBQ) at a concentration of $25 \mu \mathrm{M}$; and at 25 and $100 \mu \mathrm{M}$; inhibited 50 and $75 \%$, respectively, the electron flow measured from water to SiMo. It can be deduced that the principal inhibition site of linarin is located from the water splitting enzyme to QA because SiMo accepts electrons close to the nonheme iron in PSII. ${ }^{40}$ When increasing concentrations of 1 were assayed on PSI electron transport rate from reduced 2,6dichlorophenol indophenol (DCPIP) to MV, the results showed no-effect at any of the concentrations tested (data not shown). These results indicate that linarin inhibits at the donor site of PSII from the oxygen evolving complex (OEC) to $\mathrm{Q}_{\mathrm{A}}$.

Effect of Organic Extracts and Linarin (1) on dry Biomass of Mono- and Dicot Plants. To know and to compare the activities between the organic extracts of $Z$. affine and linarin (1) as potential post-emergence herbicides, they were sprayed on L. sativa and L. perenne plants after 15 days of growth in the greenhouse. The hexane extract did not affect dry biomass. The acetone extract at $100 \mathrm{mg} \mathrm{L}^{-1}$ inhibited the $L$. sativa biomass by $19.1 \%$, with significant differences $(p<0.05)$, however in $L$. perenne the results were not significant. The methanol extract only significantly affected the dry biomass (25.4\%) of L. perenne at $100 \mathrm{mg} \mathrm{L}^{-1}$ (Table 2).

When the effect of linarin (1) and 3-(3,4-dichlorophenyl)1,1-dimethylurea (DCMU; used as positive control) at $50 \mu \mathrm{M}$ was tested on L. sativa and $L$. perenne biomass only statistical differences for DCMU were observed (Table 3).

\section{CONCLUSIONS}

Linarin (1), lupenone (2), vitamin E (3), and affineine (4) are the major natural products isolated from $Z$. affine's aerial parts. Compound 4 is reported as natural product for the first time.
Compound $\mathbf{1}$ was obtained by precipitation directly from the acetone and methanol extracts from this plant, with $1.42 \%$ remaining in the acetone extract, and it was not detected in the hexane and methanol extracts.

Compounds $\mathbf{2}$ and 3 were identified from the hexane extract, and compound 4 was isolated from the methanol extract. Additionally, the extractś activity shown could be attributed to these compounds, respectively.

In the pre-emergence assays all three extracts from this natural source showed phytotoxic potential. In germination of L. sativa, the hexane extract was the most active; however, the root elongation in both species (L. sativa and L. perenne) was most inhibited by the acetonic extract.

Linarin (1) showed pre- and post-emergent inhibitory activities. As pre-emergent, 1 acted as germination and respiration inhibitor in $L$. sativa being selective for this dicotyledon plant. The microscopy observations showed that this compound inhibited root hair development, probably, because it affects transcription factors as well as plant hormones, so more experiments are needed.

As an in vitro post-emergent inhibitor, compound $\mathbf{1}$ acts on the photosynthetic electron flow inhibiting the PSII from the OEC to $Q_{A}$ although in vivo results are not concluding. These results suggest that $\mathbf{1}$ can be used as a lead for a potential green herbicide formulation with different targets.

\section{EXPERIMENTAL SECTION}

Plant Material. Aerial parts of $Z$. affine were collected from Atotonilco el Grande, Hidalgo, Mexico, in January 2015 and identified by M. Sci. Ramiro Rios Gómez, Facultad de Estudios Superiores Zaragoza, UNAM. A voucher specimen (number FEZA-16960) was deposited at the Facultad de Estudios Superiores Zaragoza Herbarium.

Extraction, Isolation, and Chemical Characterization of the Major Compounds from Z. affine. Dried aerial parts of $Z$. affine $(2.26 \mathrm{~kg})$ were powdered and exhaustively extracted by maceration at room temperature with hexane, acetone, and methanol. During solvent recovery of the acetone and methanol macerates, a white precipitate was obtained (3.75 g total yield). For hexane, no precipitate was found. Residual macerates, excluding the precipitate, were considered as extracts, yielding the hexane $(29.4 \mathrm{~g})$, acetone (37.6 g), and methanol $(92.3 \mathrm{~g})$ extracts.

The white precipitate structure was characterized on a Varian Mercury $400 \mathrm{MHz}$ spectrometer by ${ }^{1} \mathrm{H}$, COSY, HMBC and HSQC NMR (400 MHz), ${ }^{13} \mathrm{C}$ NMR, and DEPT (100 $\mathrm{MHz}$ ) experiments, performed at $25{ }^{\circ} \mathrm{C}$ in deuterated dimethylsulfoxide (DMSO- $d_{6}$ ) and with chemical shifts referenced to tetramethylsilane (TMS) as internal standard

Table 2. Effect of Z. affine Extracts Spraying on Leaf Dry Weight of L. sativa and L. perenne ${ }^{a}$

\begin{tabular}{|c|c|c|c|c|c|}
\hline \multirow[b]{2}{*}{ treatment } & \multirow[b]{2}{*}{ conc. $\left(\mathrm{mg} \mathrm{L}^{-1}\right)$} & \multicolumn{2}{|c|}{ L. sativa } & \multicolumn{2}{|c|}{ L. perenne } \\
\hline & & $(\mathrm{g})$ & $(\%)$ & (g) & $(\%)$ \\
\hline control & 0 & $0.54 \pm 0.03^{\mathrm{a}}$ & $100.0 \pm 5.5$ & $1.00 \pm 0.15^{\mathrm{a}}$ & $100.0 \pm 15.0$ \\
\hline \multirow[t]{2}{*}{ hexane extract } & 50 & $0.55 \pm 0.10^{\mathrm{a}}$ & $100.8 \pm 18.3$ & $0.94 \pm 0.13^{\mathrm{a}}$ & $93.3 \pm 12.9$ \\
\hline & 100 & $0.49 \pm 0.05^{\mathrm{a}}$ & $92.0 \pm 9.4$ & $0.89 \pm 0.12^{\mathrm{a}}$ & $88.5 \pm 11.9$ \\
\hline \multirow[t]{2}{*}{ acetone extract } & 50 & $0.50 \pm 0.08$ & $92.4 \pm 14.8$ & $0.95 \pm 0.15^{\mathrm{a}}$ & $94.5 \pm 14.9$ \\
\hline & 100 & $0.44 \pm 0.03^{\mathrm{b}}$ & $80.9 \pm 5.5$ & $0.96 \pm 0.22^{\mathrm{a}}$ & $95.3 \pm 21.8$ \\
\hline \multirow[t]{2}{*}{ methanol extract } & 50 & $0.55 \pm 0.03^{\mathrm{a}}$ & $100.9 \pm 5.5$ & $0.85 \pm 0.11^{\mathrm{a}}$ & $84.3 \pm 10.9$ \\
\hline & 100 & $0.47 \pm 0.04^{\mathrm{a}}$ & $86.7 \pm 7.4$ & $0.75 \pm 0.12^{\mathrm{b}}$ & $74.6 \pm 11.9$ \\
\hline
\end{tabular}

${ }^{a}$ Data represent the mean $\pm \mathrm{SD}, n=3$. Letters in each experiment show statistical difference $(p<0.05)$. 
Table 3. Effect of Linarin (1) on Leaf Dry Weight of L. sativa and L. perenne ${ }^{a}$

\begin{tabular}{|c|c|c|c|c|c|}
\hline \multirow[b]{2}{*}{ treatment } & \multirow[b]{2}{*}{ conc. $(\mu \mathrm{M})$} & \multicolumn{2}{|c|}{ L. sativa } & \multicolumn{2}{|c|}{ L. perenne } \\
\hline & & $(\mathrm{g})$ & $(\%)$ & (g) & $(\%)$ \\
\hline control & 0 & $0.51 \pm 0.04^{\mathrm{a}}$ & $100.0 \pm 7.8$ & $1.37 \pm 0.06^{\mathrm{a}}$ & $100.0 \pm 4.4$ \\
\hline DCMU & 50 & $0.29 \pm 0.03^{b}$ & $58.4 \pm 6.0$ & $0.95 \pm 0.04^{b}$ & $69.0 \pm 2.9$ \\
\hline linarin & 50 & $0.40 \pm 0.06^{\mathrm{ab}}$ & $78.6 \pm 11.8$ & $1.32 \pm 0.43^{\mathrm{a}}$ & $97.1 \pm 31.6$ \\
\hline linarin & 100 & $0.43 \pm 0.04^{\mathrm{a}}$ & $87.3 \pm 8.1$ & $1.10 \pm 0.08^{\mathrm{ab}}$ & $80.9 \pm 5.9$ \\
\hline
\end{tabular}

${ }^{a}$ Data represent the mean $\pm \mathrm{SD}, n=3$. Letters in each experiment show statistical difference $(p<0.05)$.

$(\delta=0)$. The obtained data and the comparison of its physical (melting points), spectroscopic, and spectrometric properties with those reported in literature identified this compound as linarin (1). ${ }^{27}$ This same procedure was used to identify lupenone $(2,37 \mathrm{mg})^{28}$ and vitamin $\mathrm{E}(3,35 \mathrm{mg}),{ }^{29}$ isolated by means of column chromatography (CC, hexane/acetone 9:1 and hexane/acetone 85:15) from the hexane extract and also to identify the alkaloid affineine $(4,1.1 \mathrm{~g}),{ }^{30}$ isolated by CC (acetone/MeOH 8:2) from the methanol extract. Suitable crystals of compound 4 were obtained from a 9:1 ratio mixture of $\mathrm{CH}_{2} \mathrm{Cl}_{2} / \mathrm{MeOH}$, and its structure was confirmed by X-ray analysis (CCDC 1840709). ${ }^{41}$

Quantification of Linarin (1) in Acetone and Methanol Extracts. Linarin $\left(1,2 \mathrm{mg} \mathrm{mL}^{-1}\right)$ and the extracts $\left(6 \mathrm{mg} \mathrm{mL}^{-1}\right)$ dissolved in methanol were analyzed by HPLCQ-TOF-MS (Agilent G6545, USA) using a $\mathrm{C}_{18} 1.8 \mu \mathrm{m}, 2.1 \times$ $50 \mathrm{~mm}$ column. A multigradient program with $0.01 \%$ formic acid in $\mathrm{H}_{2} \mathrm{O}-$ methanol at $0.4 \mathrm{~mL} \mathrm{~min}^{-1}$ was used as mobile phase. The complete chromatographic process was carried out at $25{ }^{\circ} \mathrm{C}$, and the injection volume was $3 \mu \mathrm{L}$. The initial ratio (8:2) was conserved for $3 \mathrm{~min}$, a first gradient was used to reach a 5:5 ratio at minute 5 , a second gradient was applied to reach a $1: 9$ ratio at minute 6.5 , flux was conserved until minute 10. At minute 10.1, the mobile phase was changed to an $8: 2$ ratio and maintained for 1 more minute. MS parameters were established as follows: $175 \mathrm{~V}$ for the fragmentor, $320{ }^{\circ} \mathrm{C}$ for gas, capillary voltage of $3500 \mathrm{~V}$, and the data were acquired on negative MS scan mode $(100-700 \mathrm{~m} / z)$. A criterion of 5000 counts was used to integrate the chromatograms. The linarin (1) sample was identified by its $\mathrm{M}, \mathrm{M}-\mathrm{H}, \mathrm{M}+\mathrm{Cl}$ and $\mathrm{M}+$ $\mathrm{HCOO}$ ions; and they were used to establish the retention time and chromatographic profile for this compound. Using this chromatographical data and the presence of the abovementioned ions, linarin was quantified in each extract. The samples were analyzed by triplicate and reported as percentage of 1 .

General Procedure to Prepare Extracts and Linarin (1) for Evaluations. Each dry extract and linarin (1) were redissolved in dimethylsulfoxide (DMSO) to prepare stock solutions at concentrations of $10 \mathrm{~g} \mathrm{~L}^{-1}$ (extracts) and $20 \mathrm{mM}$ (1). The quantity of DMSO used in each assay was less than $1 \%(\mathrm{v} / \mathrm{v})$. Aqueous solutions of extracts and 1 (50 and 100 $\mu \mathrm{M})$ were prepared from the stock solution to assay the preemergent and post-emergent activity to obtain the desired concentrations.

Additionally, $0.02 \%(\mathrm{v} / \mathrm{v})$ of polysorbate 20 was used as surfactant in the post-emergent assays. $50 \mu \mathrm{M}$ DCMU in deionized water with polysorbate $20(0.02 \% \mathrm{v} / \mathrm{v})$ was prepared as a positive control.

All negative controls were prepared by adding the major volume of DMSO (less than 1\% of DMSO) in each assay used in the preparation of samples.
Pre-emergence Assay. Seed Germination. Forty seeds of L. sativa as a model of dicotyledonous plant and L. perenne as a model of monocotyledonous plant ${ }^{33}$ were disinfected with a commercial solution of $10 \%$ sodium hypochlorite for $15 \mathrm{~min}$ in a VWR orbital shaker at $200 \mathrm{rpm}$, and then the seeds were rinsed with sterile deionized water $(\times 3)$ and placed in Petri dishes $(100 \times 15 \mathrm{~mm})$ using filter paper as support. Extracts or linarin (1) were added (final volume $10 \mathrm{~mL}$ ). All treatments were performed by triplicate in the dark at $28{ }^{\circ} \mathrm{C}$ in a chamber (Amber Hi-Lo Mod. 3554-37), 6 days for L. sativa, and 10 days for L. perenne. Germinated seeds were taken into account after $1 \mathrm{~mm}$ of root protrusion. Additionally, the length of root and stem was measured and reported as residual growth. ${ }^{38,40,41}$ Each assay was carried out in triplicate, the experiment included three independent (Petri dish) replicates per treatment in a completely randomized design. Control seed dishes contained the same amount of seeds, volume of water, and DMSO (less than 1\%) as the test solutions. Germination and residual seedling growth values (root and stem elongation) are expressed as a percentage of difference with respect to the control. Thus, zero represents the control, positive values represent growth stimulation and negative values represent growth inhibition.

Respiration. Seed respiration evaluation was carried out similar to the germination assay, but without filter paper as support. The Clark-type electrode coupled to a biological oxygen (YSI model 5300A, Yellow Spring Instrument) measured $\mathrm{O}_{2}$ uptake after $12,24,48$, and $72 \mathrm{~h}$ of treatment with linarin (1). The electric current generated during $\mathrm{O}_{2}$ reduction to water was converted to voltage; this current was stoichiometrically related to the oxygen consumed by the cathode, and the signal was registered on a chart recorder. The $\mathrm{O}_{2}$ consumption rate was calculated by the equation

$$
\begin{aligned}
& \text { nmol O}{ }_{2} \cdot \mathrm{h}^{-1} \cdot \text { seed }^{-1} \\
& =\frac{1200 \mathrm{nmol} \mathrm{O}}{20 \mathrm{~cm}} \times \frac{60 \mathrm{~min}}{1 \mathrm{~h}} \times \frac{\gamma}{1 \mathrm{~min}} \times \frac{1}{\text { number of seeds }}
\end{aligned}
$$

The rate was calculated as $\mathrm{nmol} \mathrm{O}_{2} \cdot \mathrm{h}^{-1} \cdot \operatorname{seed}^{-1}$ (where 20 $\mathrm{cm}$ on the recorder paper corresponded to $1200 \mathrm{nmol} \mathrm{O}_{2}$ and " $\gamma$ " corresponded to the recorded distances in $\mathrm{cm}$ when the $\mathrm{O}_{2}$ uptake of seeds in aqueous medium occurred) and was reported as percentage of seed respiration.

Post-emergence Assay. Determination of Dry Biomass. Fifty seeds of each model plant were placed in pots $(12 \mathrm{~cm}$ diameter) containing a mixture of soil/peat-moss/Agrolita perlita $(50: 25: 25 \mathrm{v} / \mathrm{v})$. All pots were watered on alternating days. In addition, they were maintained near to field capacity in a greenhouse at room temperature $\left(25-30{ }^{\circ} \mathrm{C}\right)$ with natural day/night illumination (12/12 h). After 15 days of emergence, they were selected and divided into three groups of plants of similar size: (1) experimental, (2) positive control, and (3) negative control. Then, plants were sprayed manually with a 
solution of one of the extracts or linarin (1) containing polysorbate $20(0.02 \% \mathrm{v} / \mathrm{v})$ as the surfactant. As a positive control, plants were sprayed with a solution containing polysorbate and DCMU, and as a negative control, they were sprayed with a solution containing polysorbate and less than $1 \%(\mathrm{v} / \mathrm{v})$ of DMSO. After 15 days, the extracts or compound were sprayed on plants; the aerial parts of all plants for each treatment were harvested at ground level and dried at $65{ }^{\circ} \mathrm{C}$ in a chamber (Binder series FD model 23). The dry biomass was weighed (resolution $0.1 \mathrm{mg}$ ) until all constant weight.

Chloroplast Isolation and Chlorophyll Quantification. Intact chloroplasts were isolated from spinach leaves (Spinacia oleracea L.) by homogenization and differential centrifugation as previously reported. ${ }^{42,43}$ Chloroplasts were suspended in 50-200 $\mu \mathrm{L}$ of the following medium: $400 \mathrm{mM}$ sucrose, $5 \mathrm{mM}$ $\mathrm{MgCl}_{2}, 10 \mathrm{mM} \mathrm{KCl}$, and $30 \mathrm{mM}$ tricine- $\mathrm{KOH}$ ( $\mathrm{pH} 8.0$ ), and they were stored as a concentrated suspension in the dark at 4 ${ }^{\circ} \mathrm{C}$, until use. The chlorophyll (Chl) concentration was determined according to Strain. ${ }^{43}$

Determination of ATP Synthesis. ATP synthesis measurements were made in freshly lysed chloroplasts $(20 \mu \mathrm{g} / \mathrm{mL} \mathrm{Chl})$ by osmotic rupture in a nonbuffered solution containing: 100 $\mathrm{mM}$ sorbitol, $10 \mathrm{mM} \mathrm{KCl}, 5 \mathrm{mM} \mathrm{MgCl} 2,0.5 \mathrm{mM} \mathrm{KCN}, 50 \mu \mathrm{M}$ $\mathrm{MV}$ as electron acceptor, $1 \mathrm{mM} \mathrm{Na}{ }^{+}$-tricine $(\mathrm{pH} 8.0), 1 \mathrm{mM}$ adenosine diphosphate (ADP) $(\mathrm{pH}$ 6.7), and the extract or linarin (1). The $\mathrm{pH}$ was adjusted to 8.0 with $50 \mathrm{mM} \mathrm{KOH}$, and the mixture was illuminated with a LED lamp of blue light (460-482 nm) for $1 \mathrm{~min}$. ATP synthesis was determined as an increase of $\mathrm{pH}$ from 8.0 to 8.1 during the illumination of chloroplasts, using a microelectrode connected to a potentiometer with expanded scale. The synthesized ATP was calculated as micromoles of ATP per milligram of Chl per hour and reported as ATP synthesis (\%).

Determination of Noncyclic Electron Transport Rate. Noncyclic electron transport (basal, phosphorylating, and uncoupled) was polarographically determined, illuminating chloroplasts $\left(20 \mu \mathrm{g} \mathrm{Chl} \mathrm{mL} L^{-1}\right)$ during $1 \mathrm{~min}$ in a medium containing $50 \mu \mathrm{M}$ of $\mathrm{MV}$ as an electron acceptor and monitored by a Clark electrode coupled to a biological oxygen monitor. ${ }^{44}$ Prior to each experiment, chloroplasts were lysed, to yield free thylakoids, by incubating them in the following basal electron transport medium: $100 \mathrm{mM}$ sorbitol, $10 \mathrm{mM}$ $\mathrm{KCl}, 5 \mathrm{mM} \mathrm{MgCl}, 0.5 \mathrm{mM} \mathrm{KCN}$, and $30 \mathrm{mM}$ tricine $(N-$ tris[hydroxymethyl]methylglycine) buffer ( $\mathrm{pH} 8.0$ with the addition of $\mathrm{KOH}$ ). Noncyclic photophosphorylation electron transport was measured using the basal electron transport medium with the addition of $1 \mathrm{mM} \mathrm{ADP}$ and $3 \mathrm{mM} \mathrm{KH}_{2} \mathrm{PO}_{4}$. Uncoupled electron transport was tested in the basal transport medium by adding $6 \mathrm{mM} \mathrm{NH} \mathrm{NH}_{4} \mathrm{Cl}$ as an uncoupler agent. ${ }^{45}$ Results are expressed as $\mu$ equivalents of $\mathrm{e}^{-} \cdot \mathrm{mg}^{-1} \cdot \mathrm{Chl}^{-1} \mathrm{~h}^{-1}$.

Electron Flow Assays: Uncoupled Photosystem II (PSII) and Uncoupled Photosystem I (PSI). These assays were performed using the same methodology as noncyclic electron transport. Reactions from water to DCPIP of uncoupled PSII were measured by the reduction of DCPIP-supported $\mathrm{O}_{2}$ evolution without MV. The medium contained $1 \mu \mathrm{M} 2,5-$ dibromo-6-isopropyl-3-methyl-1,4-benzoquinone (DBMIB), $100 \mu \mathrm{M}$ DCPIP, $300 \mu \mathrm{M} \mathrm{K}_{3}\left[\mathrm{Fe}(\mathrm{CN})_{6}\right]$, and $6 \mathrm{mM} \mathrm{NH}_{4} \mathrm{Cl}$. Partial reactions of PSII electron transport rate from water to sodium silico molybdate (SiMo) were also determined; the medium without MV was supplemented with $200 \mu \mathrm{M}$ SiMo, $10 \mu \mathrm{M} \mathrm{DCMU}$, and $6 \mathrm{mM} \mathrm{NH}_{4} \mathrm{Cl}$. SiMo accepts electrons close to the nonheme iron in PSII. ${ }^{39}$ The uncoupled PSI electron transport was determined in medium with MV, plus $10 \mu \mathrm{M}$ DCMU, which inhibits PS II at QB level, $100 \mu \mathrm{M}$ DCPIP, $300 \mu \mathrm{M}$ ascorbate, and $6 \mathrm{mM} \mathrm{NH}_{4} \mathrm{Cl}$. Results are expressed as $\mu$ equiv. $\mathrm{e}^{-} \cdot \mathrm{mg}^{-1} \cdot \mathrm{Chl}$.

Statistical Analysis. All experiments were conducted in triplicate; statistical analysis was performed using Sigma Stat 3.5 software. Germination and residual seedling growth data of each experiment (extracts and linarin) were analyzed by Kruskal-Wallis; statistical differences between treatments were compared by Holm-Sidak and Dunn's method, respectively. Respiration and dry biomass data were analyzed by one-way ANOVA, followed by comparison of mean values using Tukey method. For all analysis, a $p<0.05$ value was taken as significant.

\section{ASSOCIATED CONTENT}

\section{S Supporting Information}

The Supporting Information is available free of charge on the ACS Publications website at DOI: 10.1021/acsomega. $8 \mathrm{~b} 02020$.

1D and 2D NMR spectra of linarin, lupenone, vitamin E, affineine, and X-ray diffraction data of affineine (PDF)

\section{AUTHOR INFORMATION}

\section{Corresponding Author}

*E-mail: myolanda@uaem.mx. Phone: +52 7773297000 ext. 6024. Fax: +52 7773297997 (M.Y.R.).

ORCID $\odot$

María Yolanda Rios: 0000-0002-8875-8734

M. Ángeles Ramírez-Cisneros: 0000-0003-4696-7359

Present Address

${ }^{\S}$ Centro de Investigaciones Químicas, IICBA, Universidad Autónoma del Estado de Morelos, Av. Universidad 1001, Col. Chamilpa, 62209 Cuernavaca, Morelos, México.

\section{Notes}

The authors declare no competing financial interest.

\section{ACKNOWLEDGMENTS}

This work was supported by CONACyT (grants 241044 and 254145). All spectroscopic and spectrometric analyses were obtained from LANEM (grant number 279905).

\section{ABBREVIATIONS}

1D and 2D NMR, one- and two-dimensional nuclear magnetic resonance spectroscopy; ${ }^{1} \mathrm{H}$ NMR, proton nuclear magnetic resonance; ${ }^{13} \mathrm{C}$ NMR, carbon-13 nuclear magnetic resonance; DEPT, distortionless enhancement by polarization transfer; COSY, correlation spectroscopy; HSQC, heteronuclear single quantum coherence; $\mathrm{HMBC}$, heteronuclear multiple bond correlation; $\mathrm{MHz}$, megahertz; $\delta$, chemical shift; ATP, adenosine triphosphate; OEC, oxygen evolving complex; $Q_{A}$, quinone acceptor; PSI, photosystem I; PSII, photosystem II; L, liter; $\mathrm{mL}$, milliliter; $\mathrm{kg}$, kilogram; g, gram; DMSO- $d_{6}$, deuterated dimethylsulfoxide; TMS, tetramethylsilane; $\mathrm{CH}_{2} \mathrm{Cl}_{2}$, dichloromethane; $\mathrm{MeOH}$, methanol; CC, column chromatography; MS, mass spectrometry; $m / z$, mass divided by charge number; HPLC-Q-TOF-MS, high pressure liquid chromatography coupled with quadrupole time-of-flight mass spectrometry; $\mu \mathrm{M}$, micromolar; DCMU, 3-(3,4-dichlorophenyl)-1,1-dimethylurea; Chl, chlorophyll; CCDC, the Cambridge 
Crystallographic Data Centre; V, volt; v/v, volume/volume; $\mathrm{rpm}$, revolutions per minute; $\mathrm{mm}$, millimeter; $\mathrm{MV}$, methyl viologen; DCBQ 2,5-dichloro-1,4-benzoquinone; SiMO, sodium silico molybdate; DCPIP, 2,6-dichlorophenolindophenol

\section{ADDITIONAL NOTE}

${ }^{a}$ Copies of the data can be obtained, free of charge, on application to the Director, CCDC, 12 Union Road, Cambridge CB2 1EZ, UK (fax: +44-(0)1223-336033 or email: deposit@ccdc.cam.ac.uk).

\section{REFERENCES}

(1) Anaya, R.; Waller, A. L.; Owuor, G. R.; Friedman, O. P.; ChangHung, J.; Suzuki, C.; Arrollo-Estrada, T.; Cruz-Ortega, J. F. The role of caffeine in the production decline due to autotoxicity in coffee and tea plantations. In Allelopathy: From Molecules to Ecosystems; Reigosa, M. J., Pedrol, N., Eds.; Science Publishers, Inc.: USA, 2002; pp 7191. ISBN 1578082544.

(2) Dayan, S. O.; Duke, F. E. Clues on the search for new herbicides. In Alellopathy - A Physiological Process with Ecological Implications; Reigosa, M. J., Pedrol, N., González, L., Eds.; Springer: Netherlands, 2006; pp 63-83. ISBN 1402042795.

(3) Duke, S. O.; Dayan, F. E.; Romagni, J. G.; Rimando, A. M. Natural products as sources of herbicides: current status and future trends. Weed Res 2000, 40, 99-111.

(4) Pirani, J. R. A new species and a new combination in Zanthoxylum ( Rutaceae ) from Brazil. Brittonia 1993, 45, 154-158.

(5) Prieto, J. A.; Patiño, O. J.; Delgado, W. A.; Moreno, J. P.; Cuca, L. E. Chemical composition, insecticidal, and antifungal activities of fruit essential oils of three colombian Zanthoxylum species. Chil. J. Agric. Res. 2011, 71, 73-82.

(6) Diéguez, R.; Rivas, Y.; Prieto-González, S.; Garrido, G.; MolinaTorres, J. Potencialidad del género Zanthoxylum como fuente de agentes con actividad biológica. Acta Farm. Bonaerense 2004, 23, $243-251$.

(7) Dreyer, D. L.; Brenner, R. C. Alkaloids of some Mexican Zanthoxylum species. Phytochemistry 1980, 19, 935-939.

(8) Tantapakul, C.; Phakhodee, W.; Ritthiwigrom, T.; Yossathera, K.; Deachathai, S.; Laphookhieo, S. Antibacterial compounds from Zanthoxylum rhetsa. Arch. Pharm. Res. 2012, 35, 1139-1142.

(9) Misra, L. N.; Wouatsa, N. A. V.; Kumar, S.; Venkatesh Kumar, R.; Tchoumbougnang, F. Antibacterial, cytotoxic activities and chemical composition of fruits of two Cameroonian Zanthoxylum species. J. Ethnopharmacol. 2013, 148, 74-80.

(10) Wang, C.-F.; Yang, K.; You, C.-X.; Zhang, W.-J.; Guo, S.-S.; Geng, Z.-F.; Du, S.-S.; Wang, Y.-Y. Chemical composition and insecticidal activity of essential oils from Zanthoxylum dissitum leaves and roots against three species of storage pests. Molecules 2015, 20, 7990-7999.

(11) Wang, C.-F.; You, C.-X.; Yang, K.; Guo, S.-S.; Geng, Z.-F.; Fan, L.; Du, S.-S.; Deng, Z.-W.; Wang, Y.-Y. Antifeedant activities of methanol extracts of four Zanthoxylum species and benzophenanthridines from stem bark of Zanthoxylum schinifolium against Tribolium castaneum. Ind. Crops Prod. 2015, 74, 407-411.

(12) Christofoli, M.; Costa, E. C. C.; Bicalho, K. U.; de Cássia Domingues, V.; Peixoto, M. F.; Fernandes Alves, C. C.; Araújo, W. L.; de Melo Cazal, C. Insecticidal effect of nanoencapsulated essential oils from Zanthoxylum rhoifolium (Rutaceae) in Bemisia tabaci populations. Ind. Crops Prod. 2015, 70, 301-308.

(13) Diéguez-Hurtado, R.; Garrido-Garrido, G.; Prieto-González, S.; Iznaga, Y.; González, L.; Molina-Torres, J.; Curini, M.; Epifano, F.; Marcotullio, M. C. Antifungal activity of some Cuban Zanthoxylum species. Fitoterapia 2003, 74, 384-386.

(14) Nana, W. L.; Eke, P.; Fokom, R.; Bakanrga-Via, I.; Begoude, D.; Tchana, T.; Tchameni, N. S.; Kuate, J.; Menut, C. F.; Boyom, F. F. Antimicrobial activity of Syzygium aromaticum and Zanthoxylum xanthoxyloides essential oils against Phytophthora megakarya. J. Phytopathol. 2015, 163, 632-641.

(15) Akpheokhai, I. L.; Claudius-Cole, A. O.; Fawole, B. Evaluation of some plant extracts for the management of Meloidogyne incognita on Soybean (Glycine max). World J. Agric. Sci. 2012, 8, 429-435.

(16) Kim, J.; Seo, S.-M.; Park, I.-K. Nematicidal activity of plant essential oils and components from Gaultheria fragrantissima and Zanthoxylum alatum against the pine wood nematode, Bursaphelenchus xylophilus. Nematology 2011, 13, 87-93.

(17) Charoenying, P.; Teerarak, M.; Laosinwattana, C. An allelopathic substance isolated from Zanthoxylum limonella Alston fruit. Sci. Hort. 2010, 125, 411-416.

(18) Li, H.-Y.; Pan, K.-W.; Liu, Q.; Wang, J.-C. Effect of enhanced ultraviolet-B on allelopathic potential of Zanthoxylum bungeanum. Sci. Hort. 2009, 119, 310-314.

(19) Wu, Y. H.; Cheng, X.; Cai, Q. N.; Lin, C. W. Allelopathic effects of twelve hedgerow plant species on seed germination and seedling growth of wheat (Triticum astivum L.). Adv. Mater. Res. 2012, $356-360,2767-2773$.

(20) Dominguez, X. A.; Benavides, L.; Butruille, D. Les bases quaternaires de la racine de Zanthoxylum fagara. Phytochemistry 1974, 13,680 .

(21) Setzer, W. N.; Schmidt, J. M.; Eiter, L. C.; Haber, W. A. The leaf oil composition of Zanthoxylum fagara (L.) Sarg. from Monteverde, Costa Rica, and its biological activities. J. Essent. Oil Res. 2005, 17, 333-335.

(22) Stermitz, F. R.; Caolo, M. A.; Swinehart, J. A. Alkaloids and other constituents of Zanthoxylum williamsii. Z. monophylum and $Z$. fagara. Phytochemistry 1980, 19, 1469-1472.

(23) Snyder, J.; Nakanishi, K.; Chaverria, G.; Leal, Y.; Ochoa, C. C.; Dominguez, $\mathrm{X}$. A. The structure of castanaguyone a biisocoumarin plant product. Tetrahedron Lett. 1981, 22, 5015-5018.

(24) Amaro-Luis, J. M.; Fronczek, F. R.; Massanet, G. M.; Pando, E.; Rodríguez-Luis, F.; Watkins, S. F.; Zubía, E. Meridinol, a lignan from Zanthoxylum fagara. Phytochemistry 1988, 27, 3933-3935.

(25) Macías, V. E.; Coy, E. D.; Cuca, L. E. Novel furocarbazole alkaloids and antibacterial activity of ethanol extract from Zanthoxylum fagara (L.) Sargent. Rev. Colomb. Quim. 2010, 39, 333-341.

(26) Pérez López, L. A.; de la Torre, Y. C.; Cirio, A. T.; de Torres, N. W.; Flores Suárez, E. A.; Aranda, R. S. Essential oils from Zanthoxylum fagara Wild Lime, Ruta chalepensis L. and Thymus vulgaris L.: Composition and activity against Aedes aegypti larvae. Pak. J. Pharm. Sci. 2015, 28, 1911-1915.

(27) Shin, K. H.; Kang, S. S.; Seo, E. A.; Shin, S. W. Isolation of aldose reductase inhibitors from the flowers of Chrysanthemum boreale. Arch. Pharm. Res. 1995, 18, 65-68.

(28) Prakash, C. V. S.; Prakash, I. Isolation and structural characterization of Lupane triterpenes from Polypodium vulgare. Res. J. Pharm. 2012, 1, 23-27.

(29) Ohnmacht, S.; West, R.; Simionescu, R.; Atkinson, J. Assignment of the ${ }^{1} \mathrm{H}$ and ${ }^{13} \mathrm{C}$ NMR of tocotrienols. Magn. Reson. Chem. 2008, 46, 287-294.

(30) Francisco, M. C.; Nasser, A. L. M.; Lopes, L. M. X. Tetrahydroisoquinoline alkaloids and 2-deoxyribonolactones from Aristolochia arcuata. Phytochemistry 2003, 62, 1265-1270.

(31) Hanley, M. E.; Whiting, M. D. Insecticides and arable weeds: effects on germination and seedling growth. Ecotoxicology 2005, 14, 483-490.

(32) Kobayashi, K. Factors affecting phytotoxic activity of allelochemicals in soil. Weed Biol. Manag. 2004, 4, 1-7.

(33) OECD. Guideline for Testing of Chemicals 208, (1984). Terrestrial Plants, Growth Test, http://www.oecd.org/ chemicalsafety/risk-assessment/1948285.pdf (accessed on 4th April 2016).

(34) Charles, J.; Sancey, B.; Morin-Crini, N.; Badot, P. M.; Degiorgi, F.; Trunfio, G.; Crini, G. Evaluation of the phytotoxicity of polycontaminated industrial effluents using the lettuce plant (Lactuca 
sativa) as a bioindicator. Ecotoxicol. Environ. Saf. 2011, 74, 20572064.

(35) Ding, L.; Jing, H.-W.; Wang, T.; Li, J.; Liu, G. A. Regulation of root growth in Lactuca sativa L. seedlings by the ent-kaurane diterpenoid epinodosin. J. Plant Growth Regul. 2010, 29, 419-427.

(36) Gilroy, S.; Jones, D. L. Through form to function: root hair development and nutrient uptake. Trends Plant Sci. 2000, 5, 56-60.

(37) Narukawa, M.; Watanabe, K.; Inoue, Y. Light-induced root hair formation in lettuce (Lactuca sativa L. cv. Grand Rapids) roots at low $\mathrm{pH}$ is brought by chlorogenic acid synthesis and sugar. J. Plant Res. 2010, 123, 789-799.

(38) Morales-Flores, F.; Olivares-Palomares, K. S.; Aguilar-Laurents, M. I.; Rivero-Cruz, J. F.; Lotina-Hennsen, B.; King-Díaz, B. Flavonoids affect the light reaction of photosynthesis in vitro and in vivo as well as the growth of plants. J. Agric. Food Chem. 2015, 63, $8106-8115$.

(39) Schansker, G.; van Rensen, J. J. S. Characterization of the complex interaction between the electron acceptor silicomolybdate and Photosystem II. Photosynth. Res. 1993, 37, 165-175.

(40) Onen, H. Does allelopathy play a role in suppression of mugwort (Artemisia vulgaris) by Alfalfa? Plant Prod. Sci. 2013, 16, 255-260.

(41) Macías, F. A.; Castellano, D.; Molinillo, J. M. G. Search for a Standard Phytotoxic Bioassay for Allelochemicals. Selection of Standard Target Species. J. Agric. Food Chem. 2000, 48, 2512-2521. (42) Veiga, T. A. M.; King-Díaz, B.; Marques, A. S. F.; Sampaio, O. M.; Vieira, P. C.; da Silva, M. F. d. G. F.; Lotina-Hennsen, B. Furoquinoline alkaloids isolated from Balfourodendron riedelianum as photosynthetic inhibitors in spinach chloroplasts. J. Photochem. Photobiol. B 2013, 120, 36-43.

(43) Strain, H. H.; Cope, B. T.; Svec, W. A. Analytical Procedures for the isolation, identification, estimation, and investigation of the chlorophylls. Methods Enzymol. 1971, 23, 452-476.

(44) Izawa, S.; Hind, G. The kinetics of the $\mathrm{pH}$ rise in illuminated chloroplast suspensions. Biochim. Biophys. Acta 1967, 143, 377-390.

(45) Dean, R. L.; Miskiewicz, E. Rates of electron transport in the thylakoid membranes of isolated, illuminated chloroplasts are enhanced in the presence of ammonium chloride. Biochem. Mol. Biol. Educ. 2003, 31, 410-417. 